\title{
Numerical Analysis of a Gravity Substructure for 5 MW Offshore Wind Turbines Due to Soil Conditions
}

\author{
Min-Su Park, Youn-Ju Jeong and Young-Jun You \\ Structural Engineering Research Institute, Korea Institute of Civil Engineering and Building Technology, Goyang-Si 10223, \\ South Korea
}

Received: January 12, 2016 / Accepted: January 21, 2016 / Published: March 31, 2016.

\begin{abstract}
In order to increase the gross generation of wind turbines, the size of a tower and a rotor-nacelle becomes larger. In other words, the substructure for offshore wind turbines is strongly influenced by the effect of wave forces as the size of substructure increases. In addition, since a large offshore wind turbine has a heavy dead load, the reaction forces on the substructure become severe, thus very firm foundations should be required. Therefore, the dynamic soil-structure interaction has to be fully considered and the wave forces acting on substructure accurately calculated. In the present study, ANSYS AQWA is used to evaluate the wave forces. Moreover, the substructure method is applied to evaluate the effect of soil-structure interaction. Using the wave forces and the stiffness and damping matrices obtained from this study, the structural analysis of the gravity substructure is carried out through ANSYS mechanical. The structural behaviors of the strength and deformation are evaluated to investigate an ultimate structural safety and serviceability of gravity substructure for various soil conditions. Also, the modal analysis is carried out to investigate the resonance between the wind turbine and the gravity substructure.
\end{abstract}

Key words: Offshore wind energy, gravity substructure, suction bucket foundation, substructure method, structural analysis.

\section{Introduction}

Nowadays, the main source of energy in the world is fossil fuel. But the amount of fossil fuel is limited and the use of it causes environmental pollution and global warming. Thus, the studies of renewable energy such as hydro energy, wind energy, solar energy and geothermal energy are being carried out actively all over the world. The offshore wind energy has gained attention from many countries to find alternative and reliable energy sources, since the potential of offshore wind energy has been recognized for long and mostly associated with a nondestructive renewable energy. Therefore, many offshore wind farms are in the planning phase. Various studies have

Corresponding author: Min-Su Park, senior researcher $\mathrm{PhD}$, research field: hydrodynamics of offshore structures.

It is noted that, this paper is revised edition based on Proceedings of the ASME 2015 34th International Conference on Ocean, Offshore and Arctic Engineering, May 31-Jun. 5, 2015, Canada. been conducted on wind energy [1-3]. In order to construct the offshore wind farms, the substructures supporting offshore wind turbines have to resist loads from wind and wave. However, the size of a substructure for wind turbines is gradually increased since the size of a tower and a rotor-nacelle becomes larger with increment of gross generation. In other words, the substructure is strongly influenced by the effect of wave forces and the safety of substructure is decreased. Therefore, it is very important to accurately calculate the wave forces acting on substructures.

In addition, since a large offshore wind turbine has heavy dead loads, the reaction forces on the foundations become severe, thus very firm foundations should be required. Therefore, the dynamic soil-structure interaction has to be fully considered. There are two main methods for the analysis of dynamic structure-foundation interaction, direct and substructure methods, as outlined by Wolf $[4,5]$. 
In the present study, ANSYS AQWA is used to evaluate the wave forces acting on the gravity substructure for $5 \mathrm{MW}$ offshore wind turbine, since Morison equation cannot accurately calculate the wave forces in case of the large substructure compared to a wave length. The substructure is significantly influenced by the wave steepness and wave slamming effects but they are not considered in the present study, because the wave breaking is not occurred for the design environmental wave conditions. The wave forces and wave run up on the substructure are presented for various wave conditions. Moreover, the substructure method is applied to evaluate the effect of soil-structure interaction with impedance coefficients as damping and stiffness matrices. Using the wave forces and the stiffness and damping matrices obtained from this study, the structural analysis of the gravity substructure is carried out through ANSYS mechanical. The structural behaviors of the strength and deformation are evaluated to investigate an ultimate structural safety and serviceability of gravity substructure for various soil conditions. The first few natural frequencies of substructure are heavily influenced by the wind turbine. Therefore, the first natural frequency of substructure is to be within the soft-stiff range in between the $1 \mathrm{P}$ and $3 \mathrm{P}$ frequency ranges. The rotor frequency $(1 \mathrm{P})$ range lies between $0.115 \mathrm{~Hz}$ and $0.202 \mathrm{~Hz}$, and the blade passing frequency $(3 \mathrm{P})$ range lies between $0.35 \mathrm{~Hz}$ and $0.61 \mathrm{~Hz}$. A safety margin of $10 \%$ on the maximum and minimum rotor speed is adopted, which means that, the allowable frequency is between $0.222 \mathrm{~Hz}$ and $0.31 \mathrm{~Hz}$ [6]. Therefore, the modal analysis is carried out to investigate the resonance between the wind turbine and the gravity substructure. It is found that, the suggested gravity substructure can be an effective substructure for $5 \mathrm{MW}$ offshore wind turbines.

\section{Formulation}

The gravity substructure for $5 \mathrm{MW}$ offshore wind turbine consisted of a concrete con type superstructure and a suction bucket foundation system as shown in Fig. 1.

As the substructure mass increases, the interaction between the superstructure and foundation system intensifies, thus, the contribution to the structural response of the total system increases. An impedance function was used for analysis of the suction bucket-soil foundation system. Impedance coefficients as damping and stiffness matrices were applied to the equation of motion for the foundation system $[7,8]$.

Applying substructure method, the pile-soil foundation system can be expressed with the impedance coefficients for two-dimension such as the horizontal direction, the rotational direction and the vertical direction as shown in Fig. 2.

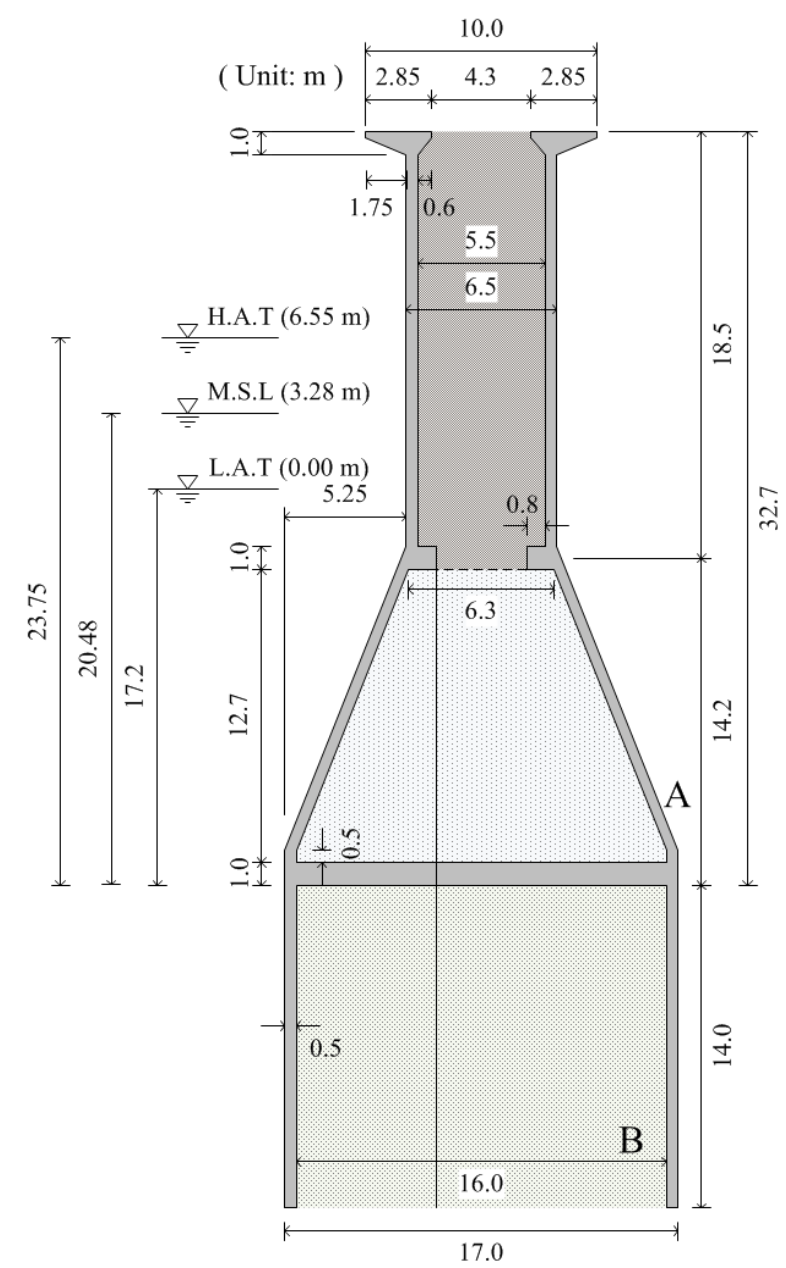

Fig. 1 Geometrical definition of the gravity substructure: HAT (highest astronomical tide), MSL (mean sea level), LAT (lowest astronomical tide). 

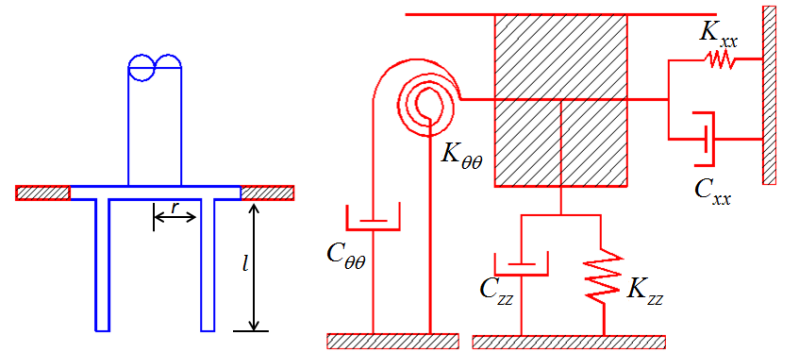

Fig. 2 Pile-soil foundation system with substructure method.

The impedance coefficient denotes the relation between the dynamic reaction force and the corresponding displacements. The impedance coefficient related to the suction bucket system on relatively soft ground conditions can be represented as follows:

$$
\begin{gathered}
{\left[K_{p}\right]=\left[\begin{array}{ccc}
K_{x x} & 0 & K_{x \theta} \\
0 & K_{z z} & 0 \\
K_{\theta x} & 0 & K_{\theta \theta}
\end{array}\right]} \\
{\left[C_{p}\right]=\left[\begin{array}{ccc}
C_{x x} & 0 & C_{x \theta} \\
0 & C_{z z} & 0 \\
C_{\theta x} & 0 & C_{\theta \theta}
\end{array}\right]}
\end{gathered}
$$

in which:

$$
\begin{aligned}
& K_{x x}=2.0 \frac{E_{p} I_{p}}{r^{3}}\left(\frac{G_{s}}{E_{p}}\right)^{0.75} \\
& K_{x \theta}=K_{\theta x}=-1.2 \frac{E_{p} I_{p}}{r^{2}}\left(\frac{G_{s}}{E_{p}}\right)^{0.5} \\
& K_{\theta \theta}=1.6 \frac{E_{p} I_{p}}{r}\left(\frac{G_{s}}{E_{p}}\right)^{0.25} \\
& K_{z z}=50 \frac{E_{p} A}{l}\left(\frac{V_{s}}{V_{p}}\right) \\
& C_{x x}=2.0 K_{x x} \frac{D_{p}}{V_{s}} \\
& C_{x \theta}=C_{\theta x}=1.5 K_{x \theta} \frac{D_{p}}{V_{s}} \\
& C_{\theta \theta}=0.5 K_{\theta \theta} \frac{D_{p}}{V_{s}} \\
& C_{z z}=K_{z z} \frac{0.026 l}{V_{s}}
\end{aligned}
$$

where, the suffixs $x, \theta$ and $z$ denote the component of horizontal direction, the component of rotational direction and the component of vertical direction, respectively. $E_{p}, G_{s}, V_{s}, D_{p}$ and $I_{p}$ are the Young modulus, the shear modulus of subsurface ground, the shear wave velocity of subsurface ground, the diameter of pile and the moment of inertia of section, respectively. The impedance coefficients $K_{p}$ and $C_{p}$ denote the stiffness matrix and the damping matrix of foundation system. The relationship between the shear strength modulus $-E_{S}$, and the shear wave velocity $-V_{s}$, is expressed as follow:

$$
G_{s}=2.0(1+v) \rho_{s} V_{s}
$$

in which, $v$ and $\rho_{s}$ denote the Poisson's ratio of soil and the density of soil, respectively.

In the present study, the stiffness and damping coefficient of single pile, which has same thickness of suction bucket, is firstly obtained and it is assumed that, the around of suction bucket is consisted of 107 piles to express the suction bucket-soil foundation system, since the general solution to calculate the stiffness and damping coefficient on the suction bucket foundation system is not well known.

\section{Numerical Results and Discussion}

\subsection{Wave Force Evaluation}

Fig. 3 shows the comparison of wave forces on gravity substructure for various water depths. The water depth of LAT, MSL and HAT is $17.2 \mathrm{~m}, 20.48 \mathrm{~m}$ and $23.75 \mathrm{~m}$, respectively. In the comparison, the calculated total wave forces are divided by incident wave amplitude (H/2). The wave forces on the gravity substructure with the water depth LAT are largest compared to the other cases. Since the wave force is closely related to the wetted surface of substructure and the water particle velocity near free surface is largest, the wave forces gradually decrease as the water depth becomes large. The peak wave force with water depth MSL and HAT decreases about $12 \%$ and $20 \%$ compared to the peak value of water depth LAT. 


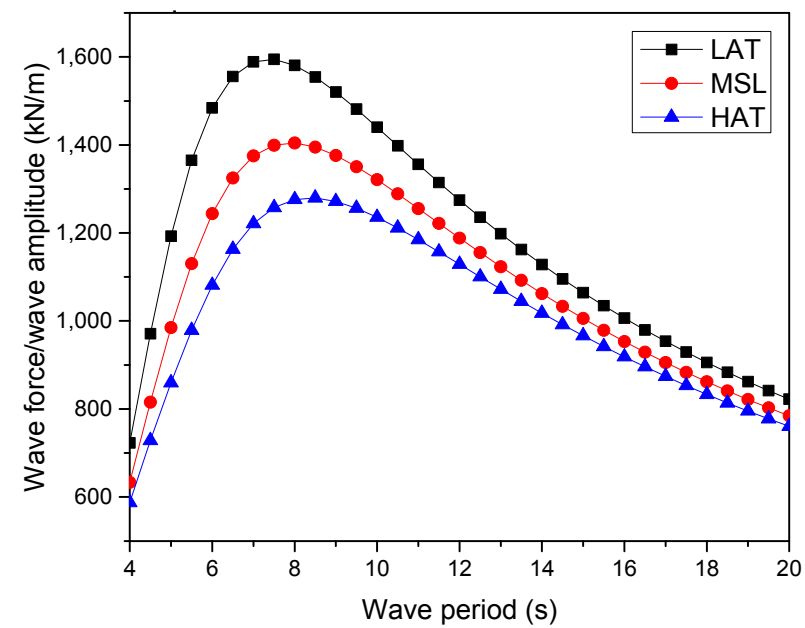

Fig. 3 Comparison of wave forces on the gravity substructure for various water depths.

Figs. 4 and 5 show the panel pressure and wave run up on gravity substructure. Since the significant wave period of southern-western sea in Korea is $12.42 \mathrm{~s}$, the comparison of those is made at the same wave period. The panel pressure near the free surface is largest and the pattern of wave run up around the substructure is very similar for all cases.

\subsection{Wind Turbine Model and Environmental Loads}

In the present study, NREL (National Renewable Energy Laboratory) 5.0 MW wind turbine model is selected for the structural safety analysis of gravity substructure. The details of NREL 5.0 MW wind turbine are provided in Table 1. The total weights of turbine and the tower model are about 350 ton and 348 ton, respectively. The hub height is $82.72 \mathrm{~m}$ from MSL and the tower length is $68.0 \mathrm{~m}$ [9]. The height of gravity substructure is $32.7 \mathrm{~m}$ from seabed and the water depth (MSL) is $20.48 \mathrm{~m}$ as shown in Fig. 1.

At the structural safety analysis, design code IEC 61400-3 is adopted and structure analysis is carried out according to the ultimate design loads condition 6.1a and 6.2a presented in Table 2. DLC (design load cases) $6.1 \mathrm{a}$ and $6.2 \mathrm{a}$ present ultimate limit states for the parked (standing still or idling) state and grid loss state, respectively.

Environmental loads of wind and wave for the

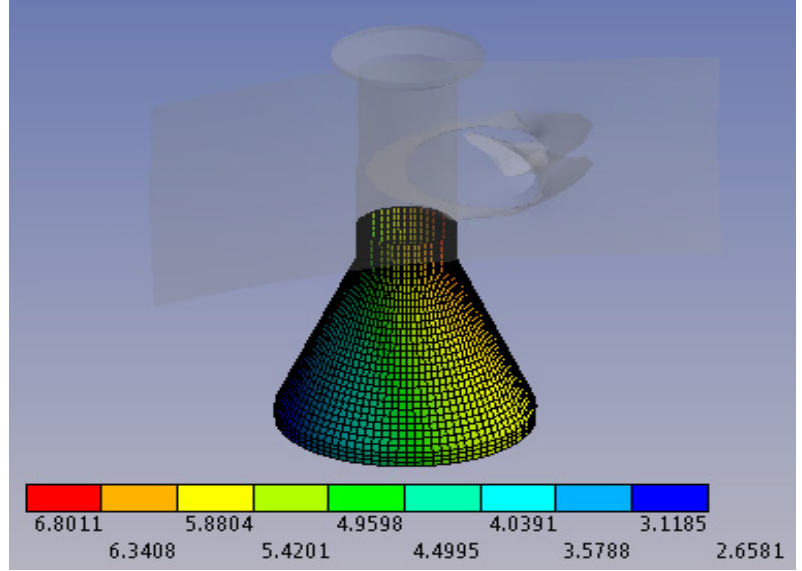

(a) Panel pressure for LAT

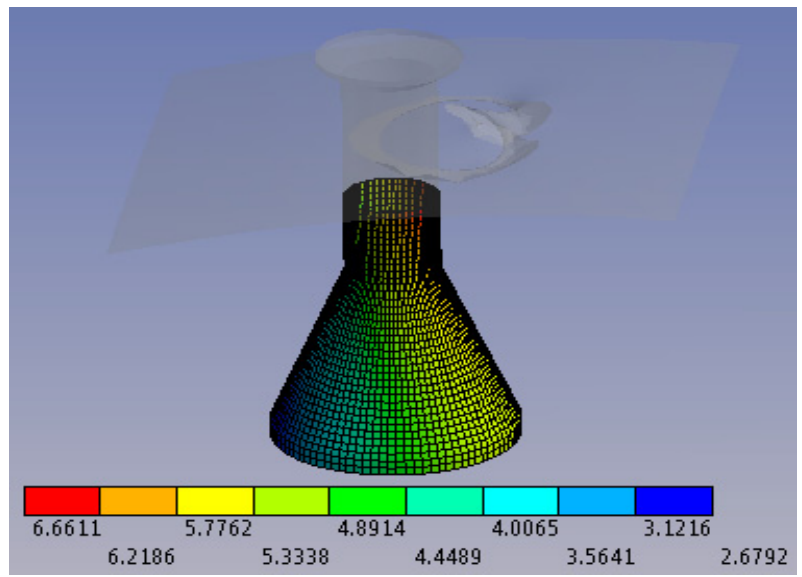

(b) Panel pressure for MSL

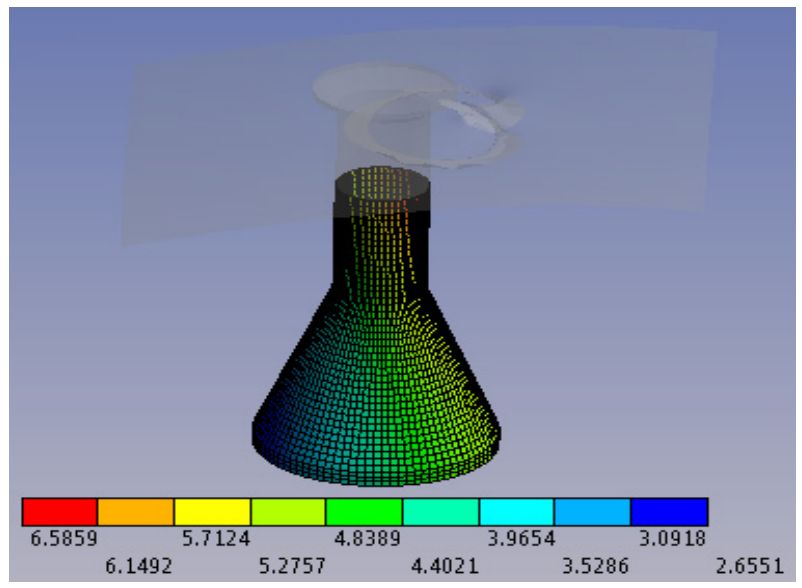

(c) Panel pressure for HAT

Fig. 4 Panel pressure on gravity substructure: (a) LAT, (b) MSL, (c) HAT.

southern-western sea of the Korea peninsular are presented in Table 3. Extreme wind and wave loads subjected to the gravity substructure are calculated based on the wind speed and the wave period of return period 50 years. 


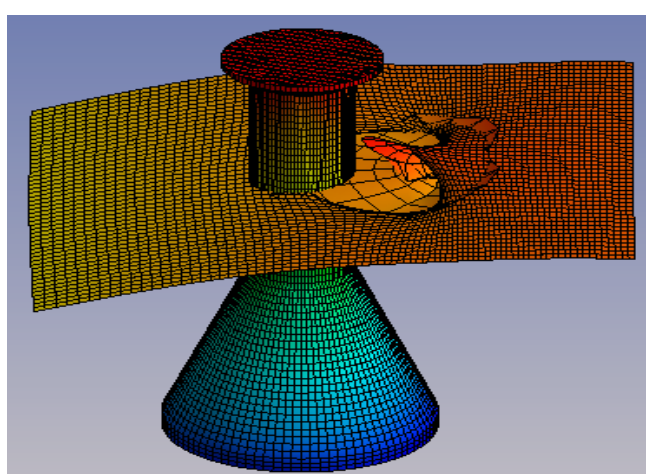

(a) Wave run up for LAT

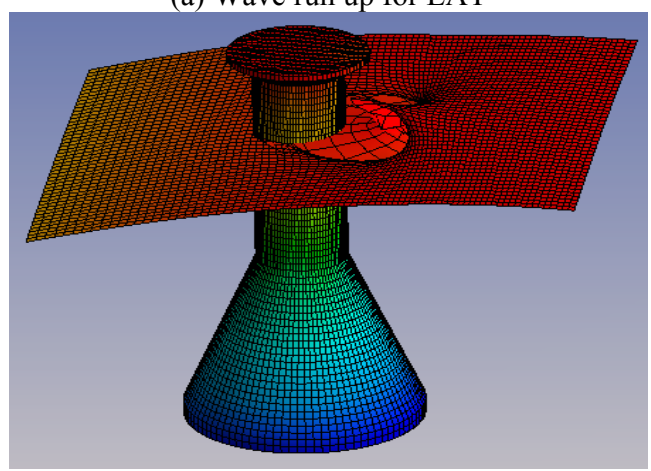

(b) Wave run up for MSL

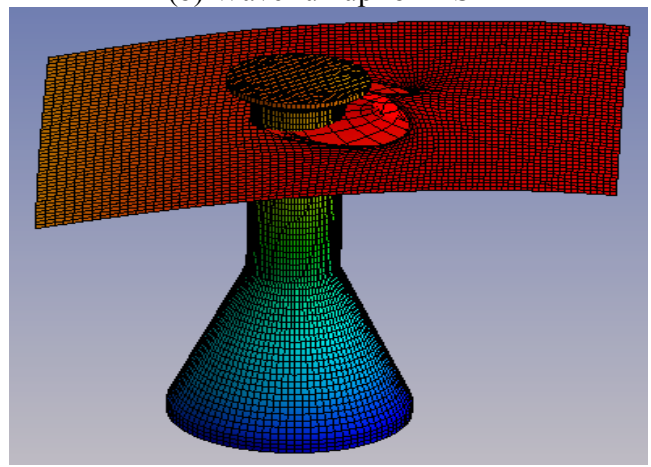

(c) Wave run up for HAT

Fig. 5 Wave run up on gravity substructure (a) LAT, (b) MSL, (c) HAT.

Table 1 Details of NREL 5 MW wind turbine model.

\begin{tabular}{lll}
\hline Turbine parameter & Unit & Value \\
\hline Rating & $\mathrm{MW}$ & 5.0 \\
Configuration & - & 3 blades \\
Rotor, hub diameter & $\mathrm{m}$ & 126,3 \\
Cut-in, rated wind speed & $\mathrm{m} / \mathrm{s}$ & $3,11.4$ \\
Cut-in, rated rotor speed & $\mathrm{rpm}$ & $6.9,12.1$ \\
Cut-out wind speed & $\mathrm{m} / \mathrm{s}$ & 25 \\
Rated tip speed & $\mathrm{m} / \mathrm{s}$ & 80 \\
Rotor mass & $\mathrm{kg}$ & 110,000 \\
Nacelle mass & $\mathrm{kg}$ & 240,000 \\
Tower mass & $\mathrm{kg}$ & 347,460 \\
Coordinate location of overall center & $\mathrm{m}$ & $(-0.2,0,64)$ \\
of mass & &
\end{tabular}

Table 2 DLC for ultimate limit state.

\begin{tabular}{llll}
\hline DLC & Condition & Wave & Wind \\
\hline IEC 61400-3-(6.1a) & $\begin{array}{l}\text { Parked standing } \\
\text { still or idling }\end{array}$ & Extreme & Extreme \\
IEC 61400-3-(6.2a) & Grid loss & Extreme & Extreme \\
\hline
\end{tabular}

Table 3 Environmental loads.

\begin{tabular}{llll}
\hline & Wind & Wave & Limit state \\
\hline Normal & \multirow{2}{*}{$7.7 \mathrm{~m} / \mathrm{s}$} & $\begin{array}{l}H_{w}=1.52 \mathrm{~m}, \\
P_{w}=6.2 \mathrm{~s}\end{array}$ & FLS (fatigue load \\
& & state) \\
Extreme & $41.6 \mathrm{~m} / \mathrm{s}$ & $\begin{array}{l}H_{w}=13.76 \mathrm{~m}, \\
P_{w}=12.42 \mathrm{~s}\end{array}$ & ULS (ultimate limit \\
\end{tabular}

\subsection{Natural Frequency and Resonance}

In order to evaluate the resonance between the wind turbine and the gravity substructure, the modal analysis is carried out. The soil conditions are expressed by using the Caltrans/NEHRP (national earthquake hazard reduction program) soil profile as shown in Table 4 [10].

Table 5 shows the stiffness and damping matrices on suction bucket-soil foundation system using substructure method. The natural frequencies and the mode shapes of gravity substructure present in Table 6 and Fig 6, respectively. Since the suction bucket stiffness increases as the shear-wave velocity of soil increases, the natural frequency is expected to increase with the velocity increments $\left(V_{s 30}\right)$. Therefore, the natural frequency of the total system is directly dependent on the soil conditions of the foundation.

The natural frequency of gravity substructure system obtained from modal analysis is plotted against

Table 4 Caltrans/NEHRP soil profile types.

\begin{tabular}{|c|c|c|c|c|}
\hline $\begin{array}{l}\text { Site } \\
\text { class }\end{array}$ & $\begin{array}{l}\text { Soil profile } \\
\text { name }\end{array}$ & $\begin{array}{l}V_{s 30} \\
(\mathrm{~m} / \mathrm{s})\end{array}$ & $\begin{array}{l}\text { Standard } \\
\text { penetration } \\
\text { test } N \text {-value } \\
\text { (bpf) } \\
\end{array}$ & $\begin{array}{l}\text { Undrained } \\
\text { shear } \\
\text { strength } \\
(\mathrm{kPa}) \\
\end{array}$ \\
\hline A & Hard rock & $>1,500$ & - & - \\
\hline B & Rock & $\geq 760$ & - & - \\
\hline $\mathrm{C}$ & $\begin{array}{l}\text { Very dense } \\
\text { soil and soft } \\
\text { rock }\end{array}$ & $\geq 360$ & $>50$ & $>100$ \\
\hline $\mathrm{D}$ & Stiff soil & $\geq 180$ & $\geq 15$ & $\geq 50$ \\
\hline $\mathrm{E}$ & Soft soil & $<180$ & $<15$ & $<50$ \\
\hline $\mathrm{F}$ & $\begin{array}{l}\text { Soil requiring } \\
\text { site specific } \\
\text { evaluation }\end{array}$ & - & - & - \\
\hline
\end{tabular}


Table 5 Stiffness and damping matrices according to $V_{s 30}$.

\begin{tabular}{lllll}
\hline$V_{s 30}$ & \multicolumn{2}{c}{$\begin{array}{c}\text { Stiffness coefficient } \\
(\mathrm{kN}, \mathrm{kN} \cdot \mathrm{m})\end{array}$} & \multicolumn{2}{c}{$\begin{array}{c}\text { Damping coefficient } \\
(\mathrm{kN} \cdot \mathrm{s}, \mathrm{kN} \cdot \mathrm{m} \cdot \mathrm{s})\end{array}$} \\
\hline \multirow{4}{*}{$90 \mathrm{~m} / \mathrm{s}$} & $K_{x x}, K_{y y}$ & $1.21 \mathrm{E}+03$ & $C_{x x}, C_{y y}$ & $6.70 \mathrm{E}+00$ \\
& $K_{z z}$ & $1.12 \mathrm{E}+08$ & $C_{z z}$ & $4.55 \mathrm{E}+05$ \\
& $K R_{x x}, K R_{y y}$ & $6.21 \mathrm{E}+05$ & $C R_{x x}, C R_{y y}$ & $8.62 \mathrm{E}+02$ \\
& $K R_{x y}, K R_{y x}$ & $1.83 \mathrm{E}+04$ & $C R_{x y}, C R_{y x}$ & $7.64 \mathrm{E}+01$ \\
\hline \multirow{3}{*}{$270 \mathrm{~m} / \mathrm{s}$} & $K_{x x}, K_{y y}$ & $6.26 \mathrm{E}+03$ & $C_{x x}, C_{y y}$ & $1.16 \mathrm{E}+01$ \\
& $K_{z z}$ & $1.12 \mathrm{E}+08$ & $C_{z z}$ & $1.52 \mathrm{E}+05$ \\
& $K R_{x x}, K R_{y y}$ & $1.08 \mathrm{E}+06$ & $C R_{x x}, C R_{y y}$ & $4.98 \mathrm{E}+02$ \\
& $K R_{x y}, K R_{y x}$ & $5.50 \mathrm{E}+04$ & $C R_{x y}, C R_{y x}$ & $7.64 \mathrm{E}+01$ \\
\hline \multirow{3}{*}{$560 \mathrm{~m} / \mathrm{s}$} & $K_{x x}, K_{y y}$ & $1.87 \mathrm{E}+04$ & $C_{x x}, C_{y y}$ & $1.67 \mathrm{E}+01$ \\
& $K_{z z}$ & $1.12 \mathrm{E}+08$ & $C_{z z}$ & $7.31 \mathrm{E}+04$ \\
& $K R_{x x}, K R_{y y}$ & $1.55 \mathrm{E}+06$ & $C R_{x x}, C R_{y y}$ & $3.46 \mathrm{E}+02$ \\
& $K R_{x y}, K R_{y x}$ & $1.14 \mathrm{E}+05$ & $C R_{x y}, C R_{y x}$ & $7.64 \mathrm{E}+01$ \\
\hline \multirow{3}{*}{$1,130 \mathrm{~m} / \mathrm{s}$} & $K_{x x}, K_{y y}$ & $5.36 \mathrm{E}+04$ & $C_{x x}, C_{y y}$ & $2.37 \mathrm{E}+01$ \\
& $K R_{x x}, K R_{y y}$ & $2.20 \mathrm{E}+06$ & $C R_{x x}, C R_{y y}$ & $2.43 \mathrm{E}+02$ \\
& $K R_{x y}, K R_{y x}$ & $2.30 \mathrm{E}+05$ & $C R_{x y}, C R_{y x}$ & $7.64 \mathrm{E}+01$ \\
\hline
\end{tabular}

Table 6 Natural frequencies of gravity substructure for various soil conditions $(\mathbf{H z})$.

\begin{tabular}{llllll}
\hline Mode & $90 \mathrm{~m} / \mathrm{s}$ & $270 \mathrm{~m} / \mathrm{s}$ & $560 \mathrm{~m} / \mathrm{s}$ & $1,130 \mathrm{~m} / \mathrm{s}$ & Fixed \\
\hline 1 & 0.1162 & 0.2219 & 0.2649 & 0.2813 & 0.3049 \\
2 & 0.2436 & 0.2635 & 0.2776 & 0.2849 & 0.3062 \\
3 & 0.3059 & 0.3875 & 0.5726 & 0.9093 & 2.2765 \\
4 & 0.8916 & 0.9097 & 1.5251 & 1.6144 & 2.2897 \\
5 & 1.7226 & 1.9418 & 2.0766 & 2.2030 & 2.6899 \\
6 & 2.0494 & 2.2414 & 2.2944 & 2.2945 & 3.8401 \\
7 & 2.3007 & 2.3261 & 3.0837 & 3.0954 & 5.4344 \\
8 & 2.9606 & 3.1019 & 3.2421 & 3.4220 & 5.4601 \\
9 & 4.0152 & 4.1879 & 4.7267 & 4.9292 & 6.1734 \\
10 & 5.0517 & 5.1409 & 5.2323 & 5.3553 & 9.0935 \\
\hline
\end{tabular}

to the spectrum density of the turbine and the environmental loads in Fig 7. It is found that, the natural frequency of gravity substructure system with more than $V_{s 30}=270 \mathrm{~m} / \mathrm{s}$ is located between the rotor frequency range $(1 \mathrm{P})$ and the blade passing frequency range $(3 \mathrm{P})$. Therefore, there is no possibility of resonance between the wind turbine and the gravity substructure with more than $V_{s 30}=270 \mathrm{~m} / \mathrm{s}$.

\subsection{Structural Results}

The loads at TP (transition pieces) due to extreme

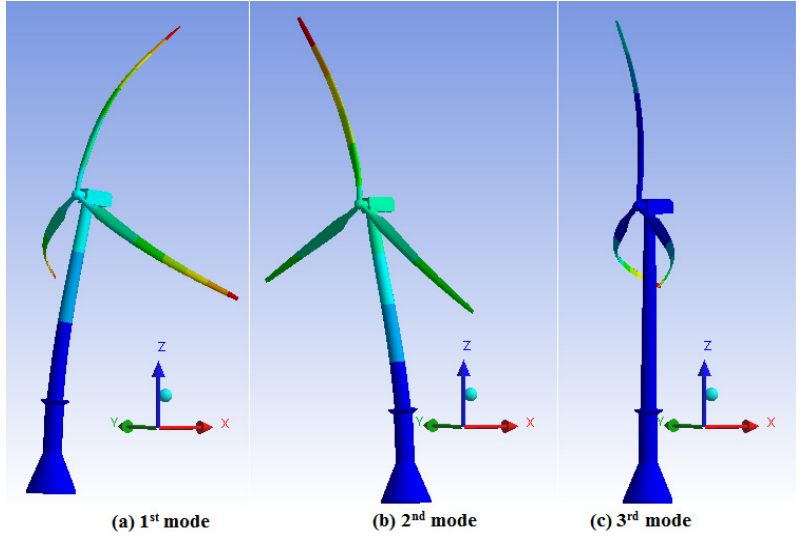

(a)

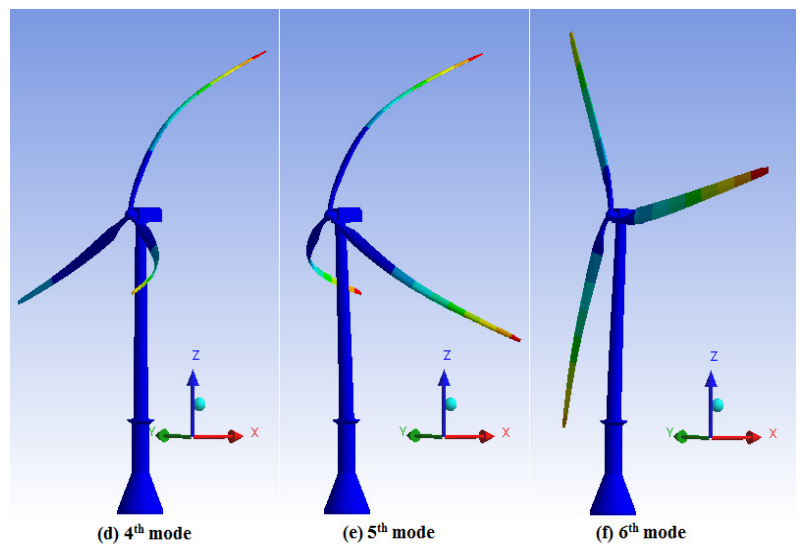

(b)

Fig. 6 Mode shapes of gravity substructure for $V_{s 30}=560 \mathrm{~m} / \mathrm{s}$.

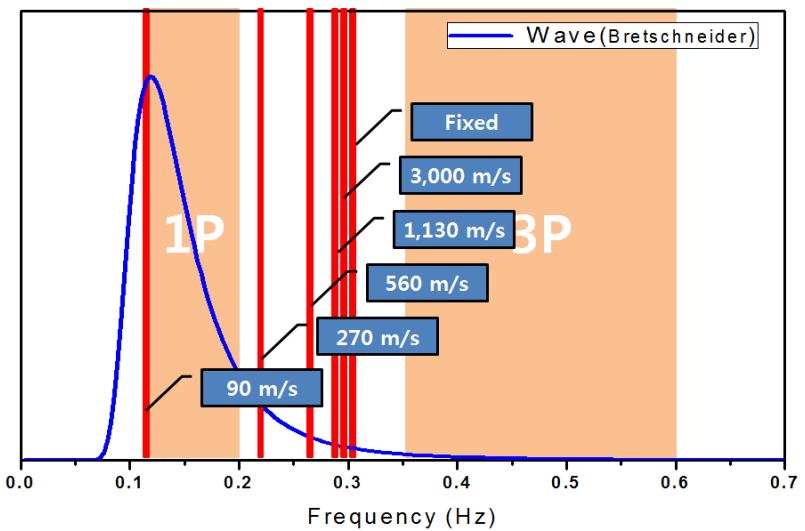

Fig. 7 Comparison of gravity substructure on the spectrum density of wind turbine and wave for various soil conditions.

wind are presented in Table 7. In the present study, the extreme values at TP for DLC 6.2a are used since they are the largest values compared to the other case. The gravity substructure is composed of concrete with $0.5 \mathrm{~m}$ thickness. The partial safety factor 1.35 is adapted for all cases [11]. 
Table 7 Extreme values at TP due to extreme wind.

\begin{tabular}{lllllll}
\hline DLC & $\begin{array}{l}F_{x} \\
(\mathrm{kN})\end{array}$ & $\begin{array}{l}F_{y} \\
(\mathrm{kN})\end{array}$ & $\begin{array}{l}F_{z} \\
(\mathrm{kN})\end{array}$ & $\begin{array}{l}M_{x} \\
(\mathrm{kN} \cdot \mathrm{m})\end{array}$ & $\begin{array}{l}M_{y} \\
(\mathrm{kN} \cdot \mathrm{m})\end{array}$ & $\begin{array}{l}M_{z} \\
(\mathrm{kN} \cdot \mathrm{m})\end{array}$ \\
\hline $6.1 \mathrm{a}$ & 324 & 225 & $-6,04$ & $-21,48$ & 3,765 & 236 \\
$6.2 \mathrm{a}$ & 1,364 & -571 & $-6,32$ & 39,827 & 82,343 & $-2,610$ \\
\hline
\end{tabular}

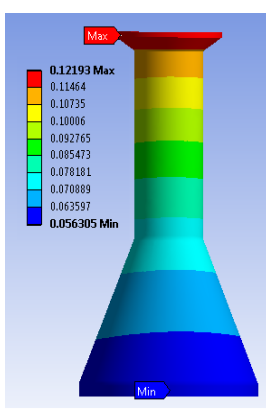

(a) LAT

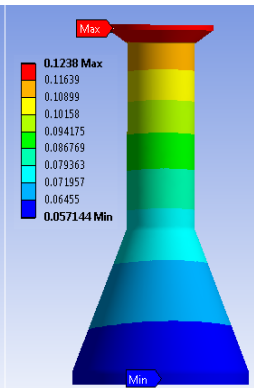

(b) MSL

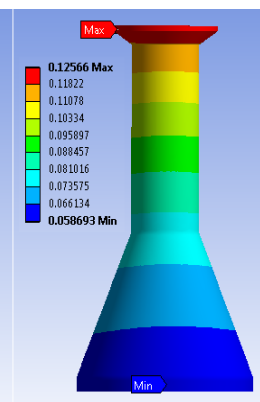

(c) HAT
Fig. 8 Structural displacement of gravity substructure due to water depth conditions (unit: $\mathbf{m}$ ).

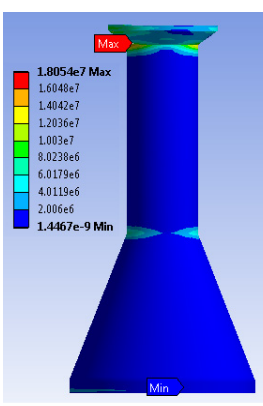

(a) LAT

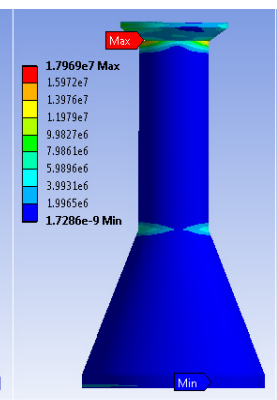

(b) MSL

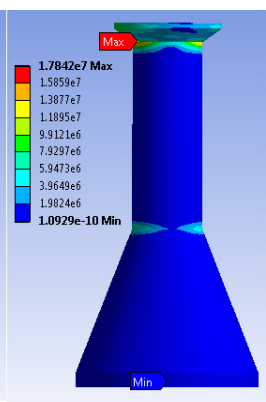

(c) HAT
Fig. 9 Structural bending stress of gravity substructure due to water depth conditions (unit: $\mathbf{P a}$ ).

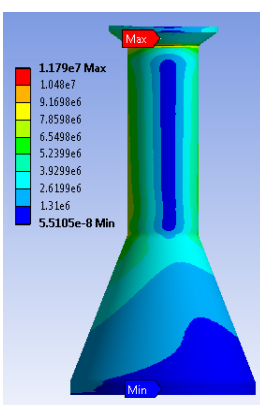

(a) LAT

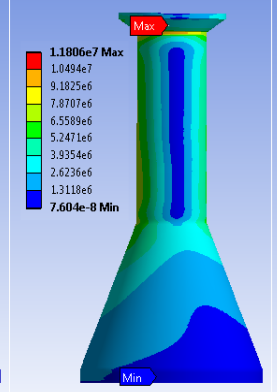

(b) MSL

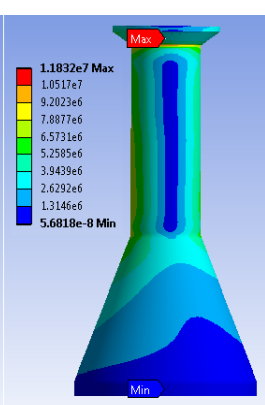

(c) HAT
Fig. 10 Structural von-Mises stress of gravity substructure due to water depth conditions (unit: Pa).

Using the wave forces from ANSYS AQWA and the wind loads at TP, the structural analysis of gravity substructure is carried out through ANSYS mechanical. For various water depths the structural displacement, the bending stress and the von-Mises stress with $V_{s 30}=560 \mathrm{~m} / \mathrm{s}$ are plotted at Figs. 8-10, respectively. Although the displacement and the von-Mises stress increase as the water depth becomes large, the bending stress decreases. The bending stress is concentrated at the connection part between circular cylinder and concrete cone. There is also large variation of bending stress. Therefore, this connection part should be examined explicitly for the reliable substructure design. The structural results are summarized at Table 8 . It is found that, the ultimate strength of gravity substructure system satisfies ULS design condition for various wave conditions.

Figs. 11-13 show the structural displacement, the bending stress and the von-Mises stress with water depth HAT for various soil conditions, respectively. Although the displacement decreases as the shear wave velocity of soil increases, the other results have very similar values. It means that, the displacement is strongly influenced by soil conditions but the structural

Table 8 Structural results due to water depth conditions.

\begin{tabular}{lllll}
\hline & & LAT & MSL & HAT \\
\hline $\begin{array}{l}\text { Displacement } \\
(\mathrm{m})\end{array}$ & Max & 0.1219 & 0.1238 & 0.1256 \\
Bending stress & Max & 0.0563 & 0.0571 & 0.0586 \\
$(\mathrm{MPa})$ & Min & $1.4 \mathrm{E}-15$ & $1.7 \mathrm{E}-15$ & $1.0 \mathrm{E}-16$ \\
Von-Mises stress & Max & 11.790 & 11.806 & 11.832 \\
$(\mathrm{MPa})$ & Min & $5.5 \mathrm{E}-14$ & $7.6 \mathrm{E}-14$ & $5.6 \mathrm{E}-14$ \\
Normal stress & Max & 3.592 & 3.560 & 3.528 \\
(x axis, MPa) & Min & -2.902 & -2.930 & -2.941 \\
Normal stress & Max & 6.859 & 6.823 & 6.769 \\
(y axis, MPa) & Min & -5.310 & -5.350 & -5.401 \\
Normal stress & Max & 7.539 & 7.580 & 7.625 \\
$(\mathrm{z}$ axis, MPa) & Min & -5.702 & -5.836 & -5.925 \\
\hline
\end{tabular}

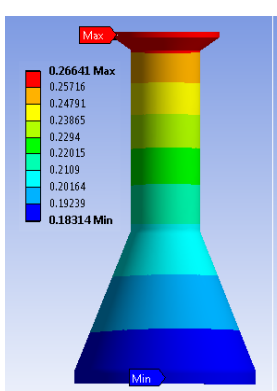

(a) $V_{s 30}=270 \mathrm{~m} / \mathrm{s}$

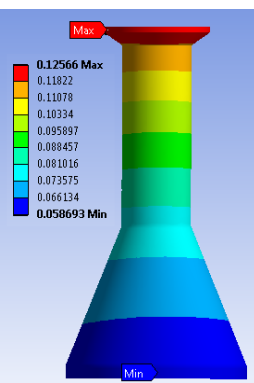

(b) $V_{s 30}=560 \mathrm{~m} / \mathrm{s}$

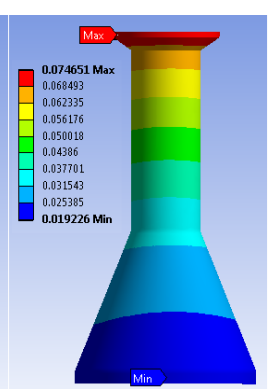

(c) $V_{s 30}=1,130 \mathrm{~m} / \mathrm{s}$
Fig. 11 Structural displacement of gravity substructure due to soil conditions (unit: $\mathrm{m}$ ). 


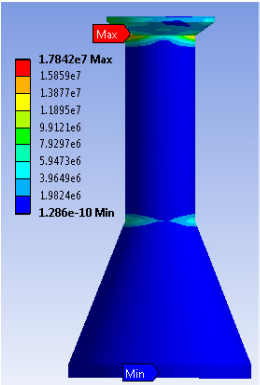

(a) $V_{s 30}=270 \mathrm{~m} / \mathrm{s}$

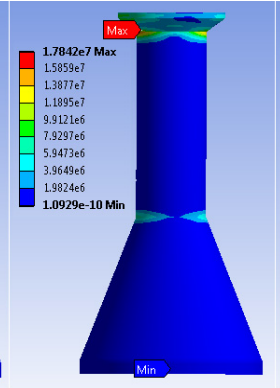

(b) $V_{s 30}=560 \mathrm{~m} / \mathrm{s}$

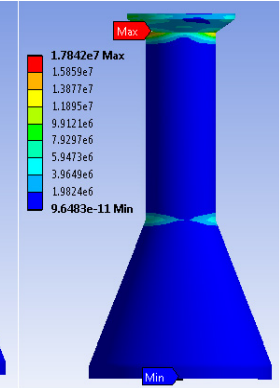

(c) $V_{s 30}=1,130 \mathrm{~m} / \mathrm{s}$
Fig. 12 Structural bending stress of gravity substructure due to soil conditions (unit: Pa).

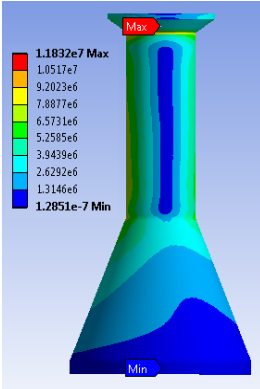

(a) $V_{s 30}=270 \mathrm{~m} / \mathrm{s}$

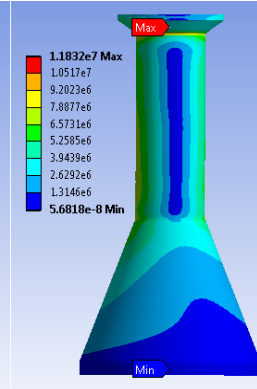

(b) $V_{s 30}=560 \mathrm{~m} / \mathrm{s}$

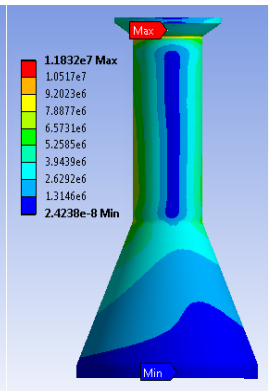

(c) $V_{s 30}=1,130 \mathrm{~m} / \mathrm{s}$
Fig. 13 Structural von-Mises stress of gravity substructure due to soil conditions (unit: Pa).

Table 9 Structural results due to soil conditions.

\begin{tabular}{|c|c|c|c|c|c|}
\hline & & $\begin{array}{l}270 \\
\mathrm{~m} / \mathrm{s} \\
\end{array}$ & $\begin{array}{l}560 \\
\mathrm{~m} / \mathrm{s} \\
\end{array}$ & $\begin{array}{l}1,130 \\
\mathrm{~m} / \mathrm{s}\end{array}$ & Fixed \\
\hline \multirow{2}{*}{$\begin{array}{l}\text { Displacement } \\
\text { (m) }\end{array}$} & Max & 0.266 & 0.125 & 0.074 & 0.026 \\
\hline & Min & 0.183 & 0.058 & 0.019 & 0.000 \\
\hline \multirow{2}{*}{$\begin{array}{l}\text { Bending stress } \\
(\mathrm{MPa})\end{array}$} & Max & 17.84 & 17.84 & 17.84 & 17.84 \\
\hline & Min & 1.E-16 & 1.E-16 & 9.E-17 & 0.000 \\
\hline \multirow{2}{*}{$\begin{array}{l}\text { Von-Mises } \\
\text { stress } \\
\text { (MPa) } \\
\end{array}$} & Max & 11.83 & 11.83 & 11.83 & 11.83 \\
\hline & Min & 1.E-13 & 5.E-14 & 2.E-14 & 0.000 \\
\hline \multirow{2}{*}{$\begin{array}{l}\text { Normal stress } \\
\text { (x axis, } \mathrm{MPa})\end{array}$} & Max & 3.528 & 3.528 & 3.528 & 3.528 \\
\hline & Min & -2.941 & -2.941 & -2.941 & -2.942 \\
\hline \multirow{2}{*}{$\begin{array}{l}\text { Normal stress } \\
\text { (y axis, MPa) }\end{array}$} & Max & 6.769 & 6.769 & 6.769 & 6.769 \\
\hline & Min & -5.401 & -5.401 & -5.401 & -5.401 \\
\hline \multirow{2}{*}{$\begin{array}{l}\text { Normal stress } \\
\text { (z axis, } \mathrm{MPa})\end{array}$} & Max & 7.625 & 7.625 & 7.625 & 7.615 \\
\hline & Min & -5.925 & -5.925 & -5.925 & -5.935 \\
\hline
\end{tabular}

stress is slightly influenced by soil conditions. The maximum bending stress and the von-Mises occurs at the connection part between TP and circular cylinder. The structural results are summarized at Table 9. For various soil conditions, the ultimate strength of gravity substructure system also satisfies ULS design condition.

\section{Conclusions}

The gravity substructure with suction bucket foundation system for $5 \mathrm{MW}$ offshore wind turbine is suggested to examine soil-structure interaction. Using the wave forces and the stiffness and damping matrices obtained from the substructure method, the structural analysis of the gravity substructure is carried out through ANSYS mechanical for various soil conditions. The results obtained from the present study are summarized as follows:

(1) Since the wave force is closely related to the wetted surface of substructure and the water particle velocity near free surface is largest, the total wave forces on gravity substructure gradually decrease as the water depth increases. Moreover, although the structural displacement is strongly influenced by soil conditions, the structural stress is slightly influenced.

(2) From the structural analysis of gravity substructure, it is found that, the gravity substructure system satisfy structural safety in respect of ULS. Also, the resonance between the wind turbine and the gravity substructure is not occurred.

(3) Consequently, the suggested gravity substructure with suction bucket foundation system can be an effective substructure for reducing hydrodynamic effects and construction costs in the southern-western sea of the Korea peninsular.

(4) In the present study, the static structural analysis is only carried out. So the linearized initial stiffness is used for the analysis. However, next step the dynamic structural analysis will be performed with the nonlinear foundation stiffness.

\section{Acknowledgments}

This research was supported by Korea Institute of Marine Science and Technology Promotion through the research project "Safety evaluation of concrete substructure systems for offshore wind power (D11206012H370000130)" and Korea Institute of Energy Technology Evaluation and Planning through the research project "Development of hybrid 
substructure systems for offshore wind power (SUBJID0000000014637)".

\section{References}

[1] Jan, W., Marte, R., Christian, S., and Edgar, G. H. 2009. "Life Cycle Assessment of a Floating Offshore Wind Turbine." Renew Energy 34 (3): 742-7.

[2] Jonkman, J. M. 2009. "Dynamics of Offshore Floating Wind Turbines-Model Development and Verification." Wind Energy 12 (5): 459-92.

[3] Lozano-Minguez, E., Kolios, A. J., and Brennan, F. P. 2011. "Multi-criteria Assessment of Offshore Wind Turbine Support Structures." Renew Energy 36 (11): 2381-7.

[4] Wolf, J. P. 1985. Dynamic Soil Structure Interaction. New Jersey: Prentice Hall, Inc.

[5] Wolf, J. P. 1988. Soil Structure Interaction Analysis in Time Domain. New Jersey: Prentice Hall, Inc.

[6] Fischer, T., De Vries, W., and Schmidt, B. 2010. Upwind Design Basis (WP4: Offshore Foundations and Support
Structures). Stuttgart: Institute of Aircraft Design Universität Stuttgart.

[7] Yamada, Y., Kawano, K., Iemura, H., and Venkataramana, K. 1988. "Wave and Earthquake Response of Offshore Structure with Soil-Structure Interaction.” Proceeding Structure Eng./Earthquake Eng. 5 (2): 361-70.

[8] Park, M. S., Koo, W. C., and Kawano, K. 2011. "Dynamic Response Analysis of an Offshore Platform Due to Seismic Motions.” Engineering Structures 33 (5): 1607-16.

[9] Jonkman, J., Butterfield, S., Musial, W., and Scott, G. 2009. "Definition of a 5 MW Reference Wind Turbine for Offshore System Development." National Renewable Energy Laboratory.

[10] Bernard, R. W., Jason, T. D., and Thomas, S. 2012. Guidelines for Estimation of Shear Wave Velocity Profile. PEER (Pacific Earthquake Engineering Research) report 2012/08.

[11] DNV (Det Norske Veritas). 2013. "DNV-OS-J101: Design of Offshore Wind Turbine Structures.” DNV. 